
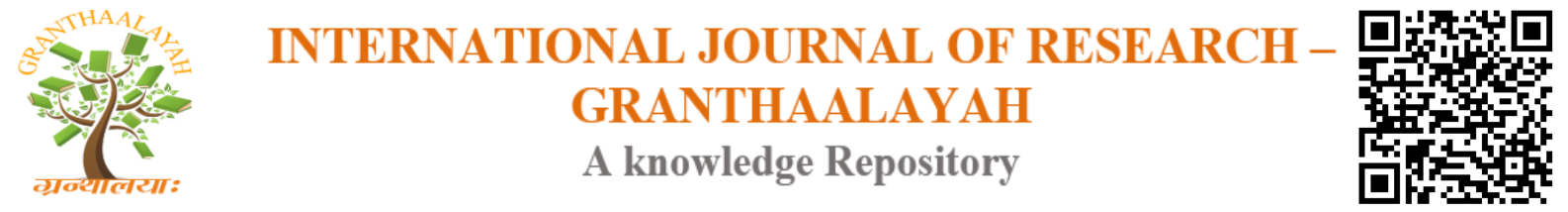

Management

\title{
COINTEGRATING RELATION BETWEEN EXCHANGE RATE AND GOLD PRICE
}

\author{
Ranjusha. $\mathbf{N}^{1}$, Dr. Devasia. M. $\mathrm{D}^{\mathbf{2}}$, Nandakumar. V. $\mathrm{T}^{3}$ \\ ${ }^{1,3}$ Research Scholar, Kannur University, India \\ ${ }^{2}$ Associate Professor, Nirmalagiri College, Kannur, India
}

\begin{abstract}
The very purpose of this paper is to analyse the relationship between gold price and Rupee Dollar exchange rate in India. The study utilises the annual data of exchange Rate (ER) and Gold Price (GP) from 1970 to 2015 to determine the relationship. Different econometric tools like Unit root test, Johansen co integration test, Vector error correction model, Granger causality test are used for detecting the long run relation, if any between the mentioned variables. The result shows that there exists a long run cointegrating relation between the variables. That is we can stabilise the Gold Price movement by controlling the exchange rate fluctuations. Likewise it also shows that Exchange rate doesn't Granger cause to Gold price and vice versa. It means that the time series data of one vasriable cannot be used to predict another.
\end{abstract}

Keywords: Exchange Rate; Gold Price; Unit Root; Cointegration; Error Correction; Granger Causality.

Cite This Article: Ranjusha. N, Dr. Devasia. M. D, and Nandakumar. V. T. (2017). "COINTEGRATING RELATION BETWEEN EXCHANGE RATE AND GOLD PRICE." International Journal of Research - Granthaalayah, 5(10), 263-269. https://doi.org/10.29121/granthaalayah.v5.i10.2017.2303.

\section{Introduction}

People consider the yellow metal as an object of luxury and a symbol of wealth. The Gold plays an important role in both the investment and consumer world. Even though gold is not considered as a primary form of currency in all countries, it has a significant influence on the value of those currencies too. That is, there exist a close correlation between the value of gold and the currencies, which are trading in foreign exchanges. Both the Gold market and Foreign exchange market attracts the investors, as it provides better opportunities for their investment and other business activities. Even though it provides a safe haven to the investors and consumers, the returns and the risks from these markets are unpredictable.

Since gold is superior to all other metals, both the developing and developed nations are frequently watching its price movements and its relationship with other financial instruments. 
That is why; many of such countries are formulating their economic policies by considering the fluctuations in Gold Prices. As US dollar is considered as the world's reserve currency, the gold price is also denominated in dollar. Therefore, the fluctuations of dollar rate have a great impact on gold price. The historical data reveals that there exist an inverse relationship between gold price and US dollar. i.e., the value of Gold rises as the price of US Dollar collapsed and vice versa.

India is considered as one of the largest gold consumer in the world. Of which, $50 \%$ of its gold demand is for wedding purposes. Besides this, people consider it as a better option for keeping their wealth. In this paper the researcher is making an attempt to analyse the relationship between Gold price and Exchange rate in India. A bulk of studies is available in this area and most of them have utilised short run data for the analysis. Whereas, the researcher here try to incorporate four decades of data for detecting whether there exists a long run relationship between the mentioned variables. The study employs 45 years' time series data i.e., from 1970 to 2015 for the analysis.

\section{Review of Literature}

Gireesh et al (2015) studied the relationship between gold price and value of exchange rate in India. The study used the spot price of gold and exchange rate for the period of $2005-2013$ and used Johansen cointegration test to check the long run relationship between these variables. The study reveals that exchange value of US Dollar is an important factor in determining the gold price in India. The appreciation or depreciation of US dollar creates fluctuations in gold price.

Subashini and Poornima (2014) examined the relationship between Gold price, Exchange rate and Crude Oil price in India by using daily data for the period of $1^{\text {st }}$ January 2009 to $31^{\text {st }}$ December 2013. The Johansen cointegration method is used to find the relationship and the result shows that Indian Rupee, gold price and crude oil price has positive relationship together. That is, an increase in currency will increase crude oil price and gold price.

Bhunia and Pakira (2014) studied the impact of gold price and exchange rate on Sensex in India by using daily data from January 1991 to October 2013. The result of Johansen cointegration test reveals that there is a long run relationship between these variables and investors are continuously watching the movements in gold price and exchange rate due to this reason.

Ibrahim et al (2014) examined the factors affecting gold price in Malaysia. They used Multiple Linear Regression Model for a 10 year data ranging from 2003 to 2012 to find the relation between variables. The study found that the exchange rate and inflation are negatively related to the gold price. At the same time crude oil price affected positively with the gold price.

Patel (2013) investigated the relationship between inflation, exchange rate and gold price in India by using monthly data from January 1991 to September 2012. The Cointegration test used in the study indicated that there exists a long run relationship between all these three variables.

Apergis and Papoulakos (2013) examined the relationship between Austrian dollar, US dollar, exchange rate and gold price by using daily data from 2000 to 2011 . They used the Error 
Correction Model and the Generalized Autoregressive Heteroskedasticity (GARCH) approach to find the association and its result shows that there is a close relationship between these two variables, and the exchange rate is acting as a reference point in fixing the future price of gold.

Tufail and Batool (2013) analysed the relationship between inflation and gold price in Pakistan. Here they applied the cointegration test for the time series data from 1960-2010 to find the relationship and the result indicates that gold is a crucial determinant of inflation in Pakistan.

Omag (2012) studied the relationship between gold price and selected financial variables in Turkey. He used Regression model to analyze the relationship between variables from January 2002 to December 2011. The result indicates that there is a positive relationship between the gold price, Istanbul Stock Exchange 100 Index and the exchange rate between Turkish Lira and the Dollar.

Arezki et al (2011) investigated the relationship between South African Rand and gold price volatility by using monthly data ranging from 1980 to 2010 . The cointegration method is used to find out the relation between variables. The result shows that the gold price fluctuation is less important to the South African Rand especially after the liberalization and their economy is less depending on gold and its price variations.

Sjaastad (2008) investigated the theoretical and empirical relationship between gold price and major exchange rates using data for January 1991 to June 2004 period. They used the asset pricing model to predict the relation, and the result reveals that the emergence of flexible exchange rate system created instability in the world gold market, and now it is dominated by the US dollar. That means, any change in the value of US dollar creates a strong impact on the price of Gold.

\section{The Methodology}

The study utilises the annual data of exchange Rate (ER) and Gold Price (GP) from 1970 to 2015. The time series data are extracted from Reserve Bank of India Bulletin. The variable Exchange Rate is expressed as rupee per unit of US dollar and the average of each year is chosen as proxy. Similarly, Gold Price is expressed as the average rupee per 100 grams of gold at Mumbai. Prior to applying econometric analysis both of these variables are converted into logarithmic forms. It is indicated as LNGP and LNER.

The study applied different econometric tools like Unit root test, Johansen cointegration test, vector error correction model and Granger causality test for detecting the long run relation between the mentioned variables.

\section{Discussion}

The time series data are plotted in figure 1 and 2. To examine the non-stationarity property of the series, the study utilizes unit root test. Here the researcher used two kinds of unit root test viz; Augmented Dicky Fuller test and Philip Perron test. 

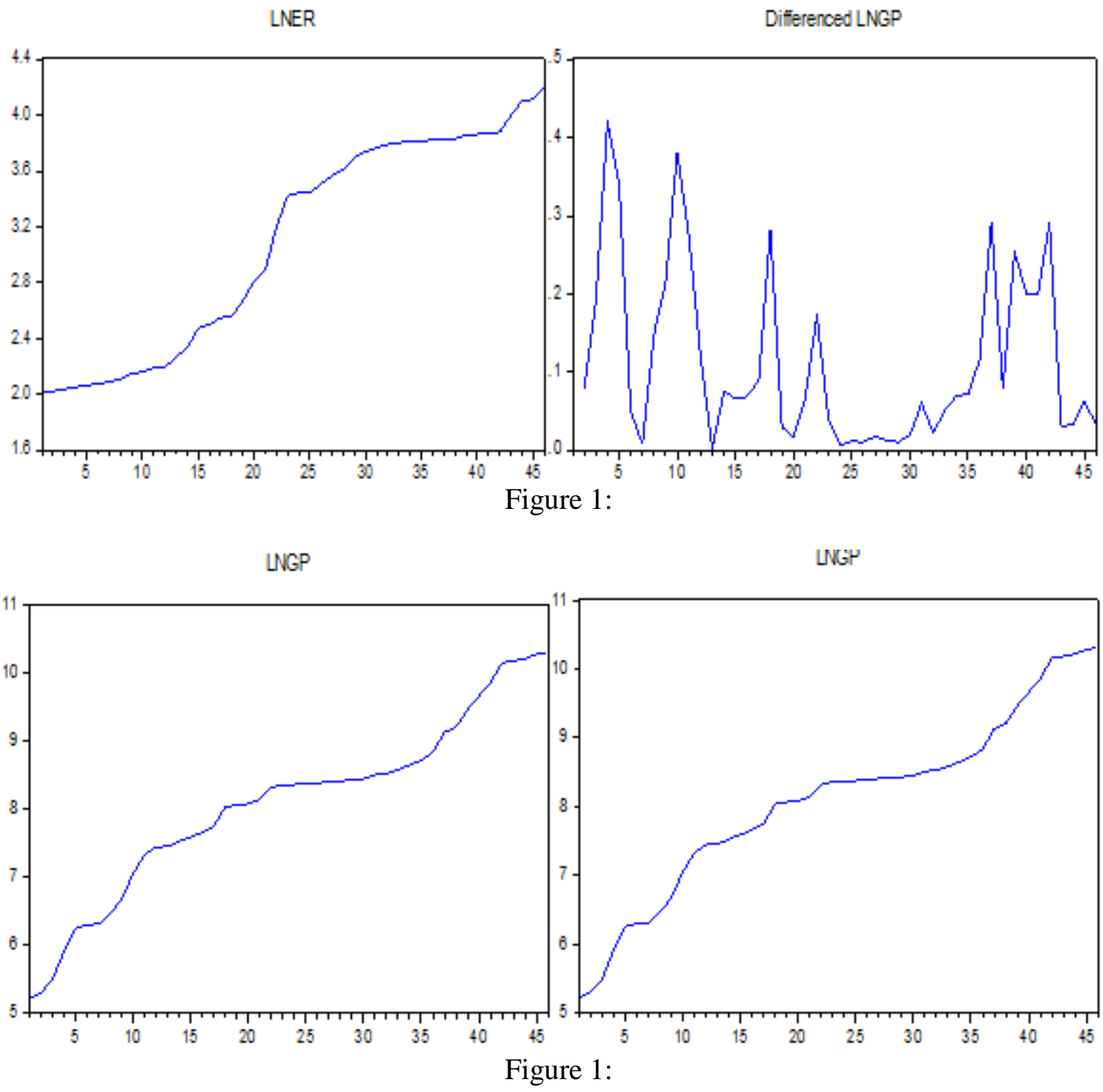

The result of the unit root test is shown in table 1. It shows that both the variables are found to have a unit root at level. The Augmented Dicky Fuller test reveals that Exchange rate is nonstationary at level. It cannot reject the null hypothesis of unit root as the critical value ($3.515523)$ is greater than the ADF statistics (-1.1762130). At the same time, it is stationary at its first difference. The Philips Perron (PP) test also gives the same result.

For the variable Gold price, the null hypothesis of unit root cannot be rejected at its level as its ADF t value (-2.995441) is less than the critical value (-3.515523). This indicates that, a unit root is found at its level. Both the ADF test and PP test shows the series has stationary at its first difference. Thus, both variables are I (1) series. 
Table 1: Result of the Unit root test

\begin{tabular}{|c|c|c|c|c|}
\hline & Augmented Dicky Fuller Test & \multicolumn{2}{c|}{ Phillip Perron Test } \\
\hline & Level & First Difference & Level & First Difference \\
\hline & & & & \\
LNER & $-1.762130(0.7059)$ & $-3.895432(0.0206)^{*}$ & $-1.613694(0.7718)$ & $-3.895432(0.0206)^{*}$ \\
\hline LNGP & $-2.995441(0.1450)$ & $-4.011751(0.0154)^{*}$ & $-2.214511(0.4703)$ & $-4.010741(0.0154)^{*}$ \\
\hline
\end{tabular}

\section{Cointegration Test}

As the time series are integrated with same order, the next task is to detect whether there exists a long run relation between them. It can be estimated through Johansen cointegration test. Prior to applying the cointegration test, the optimal lag length of the model must be determined. Number of criteria such as Hannan-Quinn Information (HQ), Akaike Information Criteria (AIC) and Schwarz Information Criteria (SIC) are used to detect the lag length. All these criterions recommend that the lag length of the model is 2 . It is expressed in table 2

Table 2: Lag length criteria

\begin{tabular}{|l|l|l|l|}
\hline Lag length & \multicolumn{1}{|c|}{ AIC } & \multicolumn{1}{c|}{ SC } & \multicolumn{1}{c|}{ HQ } \\
\hline 0 & 3.603939 & 3.686686 & 3.634269 \\
\hline 1 & -4.370727 & -4.122488 & -4.279737 \\
\hline 2 & $-4.613839 *$ & $-4.200108^{*}$ & $-4.462190^{*}$ \\
\hline 3 & -4.553057 & -3.973834 & -4.340749 \\
\hline 4 & -4.464590 & -3.719874 & -4.191622 \\
\hline
\end{tabular}

The results of Johansen cointegration test are depicted in table 3. It identifies one cointegrating vector for the model. Put in another way, both the Trace test and the maximum Eigen value test recommends a long run relation between the variables - Exchange rate and Gold price. It reject the null hypothesis of $r=0$ at $5 \%$ level of significance. The normalized cointegrating equation of the model is given below.

Table 3: Result of the Johansen Cointegration test

\begin{tabular}{|c|c|c|c|}
\hline Hypothesis & Eigen Value & $\boldsymbol{\lambda}$ Trace & $\boldsymbol{\lambda}$ max \\
\hline $\mathrm{r}=0$ & 0.343777 & $25.94074(0.0491)^{*}$ & $19.53518(0.0462)^{*}$ \\
\hline $\mathrm{r} \leq 1$ & 0.110365 & $5.145560(0.5756)$ & $5.145560(0.5756)$ \\
\hline
\end{tabular}

LNGP $=-2.890499+1.692337$ LNER

$(0.24017)$

$[-7.04654]$

The above equation found that, there is a long run relation exists between Exchange rate and Gold price. Both are positively correlated. A percentage rise in LNER leads to a $1.69 \%$ rise in LNGP. It indicates that, domestic gold price depends on the variations in the country's Exchange rate. The vector error correction model is expressed in the following equation. The coefficient of the cointegrating equation depicts the long run relationship between the variables while the Error 
Correction term in the VECM equation shows the speed adjustment of the short run dynamics to the long run equilibrium time path].

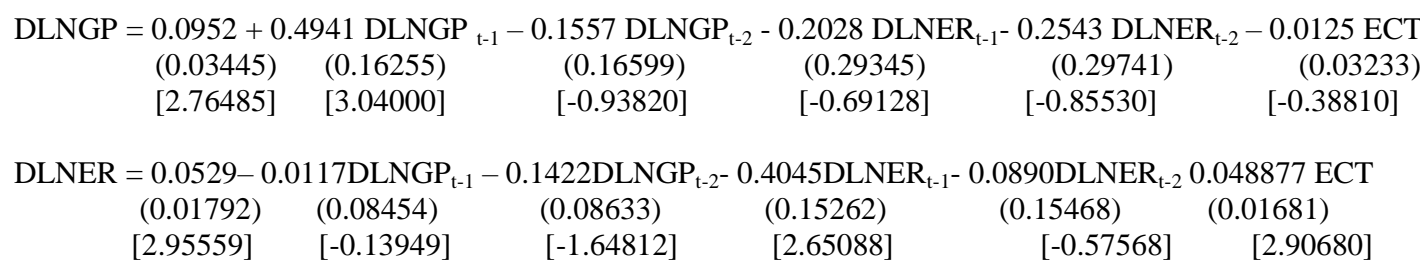

The sign of the Error Correction term in the above equation is negative but not significant. The value of the Error Correction term (-0.0125) suggest that in the long run both LNER and LNGP converges towards equilibrium.

\section{Granger Causality / Block Exogenity Wald Test}

The Granger Causality test is employed to identify the causal relationship between the two variables Gold price and Exchange rate. As the $\mathrm{P}$ value of one variable, say Exchange rate significantly contribute to forecast the value of the other variable Gold price, Then it can be stated that the Exchange rate Granger cause with the Gold price and vice versa.

The result of the Granger Causality / Block Exogenity Wald test rejects such causality between the variables. It is depicted in the table (4) below. Here LNGP doesn't Granger cause to LNER. Similarly, the LNER doesn't Granger cause to LNGP.

Table 3: VEC Granger Causality/Block Exogeneity Wald Tests Dependent variable: D (LNGP)

\begin{tabular}{|c|c|c|c|}
\hline Excluded & Chi-sq & Df & Prob. \\
\hline D(LNER) & 2.064461 & 2 & 0.3562 \\
\hline \multicolumn{4}{|c|}{ Dependent variable: D (LNER) } \\
\hline Excluded & Chi-sq & Df & Prob. \\
\hline D(LNGP) & 3.357024 & 2 & 0.1867 \\
\hline
\end{tabular}

\section{Conclusion}

In this paper, the Researcher tries to find out the linkage or long run relationship, if any exists between Gold price and Exchange rate in India. The study found that there is a long run cointegrating relation exists between the mentioned variables. The deviation from long run equilibrium is corrected gradually through a series of partial short run adjustments. It means that we can stabilise the Gold Price movement by controlling the Exchange Rate fluctuations. And the result of granger causality reveals that there is no causal relationship exists between the two variables, so the time series data of one variable cannot be used to predict another.

\section{References}

[1] Apergis, N. and Papoulakos, D. (2013), The Australian dollar and gold price, The Open Economics Journal, Vol.6, Pp. 1 - 10. 
[2] Arezki. R., Freytag. A. and Quintyn. M. (2011), Gold price volatility and the South African Rand, Working Paper, Pp.1 - 10.

[3] Bhunia, A. and Pakira, S. (2014), Investigating the Impact of Gold price and Exchange rate on Sensex, Europian Journal of Accounting, Finance and Business, Vol. 2, Issue.1, Pp. 1 - 11.

[4] Ibrahim, S.N., Kamaruddin, N.I. and Hasan, R. (2014), Determinants of gold price in Malaysia, Journal of Advanced Management Science, Vol.2, No.1, Pp.38 - 41.

[5] K.N, Girish., Choudhari, N. and Purohit H. ( 2015), The relationship between gold prices and exchange value of US Dollar in India, Emerging market Journal, Vol.5, No.1, Pp.17 - 25

[6] Omag. A. (2012), An observation of the relationship between gold prices and selected financial variables in Turkey, The Journal of Accounting and Finance, Pp.195 - 206.

[7] Patel, S.A. (2013), Gold as a strategic prophecy against inflation and exchange rate, Working Paper, Business Perspective and Research.

[8] Sjaastad, L.A. (2008), The price of gold and exchange rates: once again, Working Paper, Pp. 1 14.

[9] Subhashini, S. and Poornima. S. (2014), An empirical investigation of the causal relationship between Gold price, Exchange rate and Crude oil price, International Journal of Management Research and Review, Vol.4, Issue .10. Pp. 981 - 987.

[10] Tufail, S. and Batool, S. (2013), An analysis of the relationship between inflation and gold price: evidence from Pakistan, The Lahore Journal of Economics, 18:2, Pp. 1 - 35.

\footnotetext{
*Corresponding author.

E-mail address: vtnandakumarclt@ gmail.com
} 